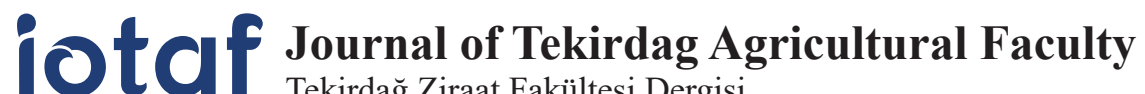 \\ Tekirdağ Ziraat Fakültesi Dergisi
}

Ocak/January 2019, 16(1)

Başvuru/Received: 19/10/17

Kabul/Accepted: $28 / 02 / 18$

DOI: $10.33462 /$ jotaf.516848

http://dergipark.gov.tr/jotaf http://jotaf.nku.edu.tr/

\section{Farklı Bitki Uçucu Yağların Erwinia amylovora'ya Karşı Antibakteriyel Etkisinin Belirlenmesi}

\author{
Determination of Antibacterial Effect of Different Plant Essential Oils Against Erwinia \\ amylovora
}

\section{Benian Pınar AKTEPE ${ }^{1}$, Kerem MERTOĞLU², Yasemin EVRENOSOĞLU², Yeşim AYSAN ${ }^{3, *}$}

\begin{abstract}
Öz
Erwinia amylovora'nın neden olduğu ateş yanıklığı hastalığı Rosaceae familyasına ait 39 farklı cins ve 128 türe ait bitkide hastalık oluşturmaktadır. Bu hastalıkla mücadelede farklı yöntemler kombine halde kullanılarak entegre hastalık yönetimi tercih edilir. Son yıllarda hastalığın mücadelesinde alternatif yöntemlerin araştırılması üzerine çalışmalar yoğunlaşmıştır. Bu yöntemlerden birisi de tıbbi ve aromatik bitkilerden elde edilen uçucu yağlardır. Bu çalışmada, 16 farklı bitki uçucu yağın, Erwinia amylovora'ya karşı antibakteriyel etkisi in vitro koşullarda araş̧ırıılmıştır. Çalışmada, yedi farklı bitkinin (Allium sativum, Cinnamomi ceylanici, Cymbopogon citratus, Lavandula officinalis, Mentha arvensis, Syzygium aromaticum ve Thymus vulgaris) uçucu yağı Erwinia amylovora'nın in vitro koşullarda gelişimini engellemede başarlı olmuştur. Cymbopogon citratus uçucu yağı hariç diğer altı bitkinin uçucu yağı streptomisin antibiyotiğinden kuvvetli antibakteriyel etkiye sahip olmuştur. Allium sativum, Cinnamomi ceylanici ve Mentha arvensis uçucu yağlarında sırasıyla 16.44, 15.11 ve $12.94 \mathrm{~mm}$ inhibisyon zonu elde edilmiş ve bu uçucu yağlar güçlü antibakteriyel etkilerle dikkat çekici bulunmuştur. Etkili bulunan bu uçucu yağlar, hastalığın mücadelesinde umut verici olarak değerlendirilmiştir.
\end{abstract}

Anahtar Kelimeler: Uçucu yă̆, Erwinia amylovora, Allium sativum, Cinnamomi ceylanici, Mentha arvensis

\begin{abstract}
Fire Blight caused by Erwinia amylovora is a disease of plants belonging to Rosaceae family of 39 different genera and 128 species. Integrated disease management is preferred by combining different methods in the disease control. Nowadays, studies on alternative methods to control of the disease were intensified. One of these methods is using of essential oils obtained from medical and aromatic plants. In this study, antibacterial activity of 16 different plant essential oil was investigated against to Erwinia amylovora in vitro conditions. Seven essential oils (Allium sativum, Cinnamomi ceylanici, Cymbopogon citratus, Lavandula officinalis, Mentha arvensis, Syzygium aromaticum and Thymus vulgaris) inhibited successfully the growth of Erwinia amylovora in vitro conditions. The higher antibacterial efficacy was produced by the six plant essential oil except Cymbopogon citratus, compared to streptomycin. Essential oils from Allium sativum, Cinnamomi ceylanici and Mentha arvensis were obtained in 16.44, 15.11 and $12.94 \mathrm{~mm}$ inhibition zones, respectively and these essential oils had the highest antibacterial effects. These effective essential oils was found as promising in this disease control.
\end{abstract}

Keywords: Essential oil, Erwinia amylovora, Allium sativum, Cinnamomi ceylanici, Mentha arvensis

\footnotetext{
'Benian Pınar Aktepe, Osmaniye Korkut Ata Üniversitesi, Organik Tarım İşletmeciliği Bölümü, 80760 Osmaniye. E-mail: benianaktepe@osmaniye.edu.tr (D) OrcID: 0000-0002-4731-9954

${ }^{2}$ Kerem Mertoğlu, Eskişehir Osmangazi Üniversitesi, Bahçe Bitkileri Bölümü, 26160 Eskişehir. E-mail: kmertoglu@ogu.edu.tr (DD OrcID: 0000-0002-0490-9073 ${ }^{2}$ Yasemin Evrenosoğlu, Eskișehir Osmangazi Üniversitesi, Bahçe Bitkileri Bölümü, 26160 Eskișehir. E-mail: yevrenosoglu@ogu.edu.tr (DD OrcID: 000-002-02128492

3**Sorumlu Yazar/Corresponding Author: Yeşim Aysan, Çukurova Üniversitesi, Bitki Koruma Bölümü, 01330 Adana. E-mail: aysanys@gmail.com (DD OrcID: 0000-0003-2647-5111

Atıf/Citation: Aktepe, B.P., Mertoğlu, K., Evrenosoğlu, Y., Aysan, Y. Farklı bitki uçucu yağların Erwinia amylovora'ya karşı antibakteriyel etkisinin belirlenmesi, Tekirdăg Ziraat Fakültesi Dergisi, 16(1), 34-41.
}

CBu çalışma Tekirdağ Namık Kemal Üniversitesi tarafından Creative Commons Lisansı (https://creativecommons.org/licenses/by-nc/4.0/) kapsamında yayınlanmıștır. Tekirdağ 2019 


\section{Extended Summary}

Erwinia amylovora, caused by fire blight disease, is a pathogenic bacterium that can infect the entire subsoil and aboveground parts of the plant species belonging to the Maloideae subfamily and cause the death of the whole plant because it acts systemically (Vanneste 2000; Gaaliche ve ark., 2017). It is also difficult to control of this pathogen which causes a destructive infection by progressing rapidly on all parts of the plant. Due to phytotoxic effect of copper preparations, especially in vegetative period, antibiotic resistance problem and not being licensed in our country have made us to do research on the use of alternative methods in the struggle of the disease. One of these methods is the essential oils obtained from medicinal and aromatic plants, which are considered as natural antibiotics. Herbal essential oils, which have strong antibacterial activity and are environmentally friendly, have provided promising results in the control of this disease. Studies investigating the antibacterial effects of different volatile oils against Erwinia amylovora have been reported to suppress pathogen development (Scortichini ve Rossi, 1989; Scortichini ve Rossi, 1991; Basım ve ark., 2000; Basım ve Basım, 2004; Kokoskova ve Pavela, 2007; Karami-Osboo ve ark., 2010; Kokoskova ve ark., 2011; Salem ve ark., 2014). In this study, the antibacterial effect of essential oils obtained from medicinal and aromatic plants against Erwinia amylovora was investigated in vitro condition. The study included sage (Salvia officinalis), rosemary (Rosmarinus officinalis), laurel (Laurus nobilis), rose (Rosa sp.), Nettle (Urtica sp.), Clove (Caryophyllus aromaticum), thyme (Thymus vulgaris), lavender (Lavandula angustifolia) lemon (Citrus limonum), lemon grass (Cymbopogon citratus), mint (Mentha arvensis), fennel (Foeniculum vulgare), garlic (Allium sativum), cinnamon (Cinnamomi gazelle), kitten (Artemisia absinthium) and ginger (Zingiber officinale) essential oils are used. As a result of in vitro tests, 11 of 16 essential oils were found to have antibacterial activity against Erwinia amylovora with an inhibition zone of 1.11 to $16.44 \mathrm{~mm}$. The antibiotic streptomycin, which was used as a positive control, produced an average of 5.11 $\mathrm{mm}$ of inhibition zone. At the end of the study, Allium sativum, Mentha arvensis, Cinnamomi gazerici, Thymus vulgaris, Lavandula officinalis, Syzygium aromaticum and Cymbopogon citratus were found to be successful in inhibiting the growth of Erwinia amylovora. Application with the strongest antibacterial effect was obtained from Allium sativum essential oil with $16.44 \mathrm{~mm}$ inhibition zone. This application was followed by Mentha arvensis with $15.11 \mathrm{~mm}$ inhibition zone and Cinnamomi anticancer essential oils with $12.94 \mathrm{~mm}$ blocking zone and they were the more effective than streptomycin antibiotic. The strong effect of these essential oils is thought to be due to the antibacterial effect of the chemicals forming the components against Erwinia amylovora.

Various extracts and/or their essential oils obtained from medicinal and aromatic plants serve as natural bactericides and use as a part of an integrated struggle in the control of plant bacterial diseases is seen as a promising alternative. The active ingredients of these essential oils contribute to the emergence of new chemicals in agriculture. The active ingredients of these essential oils contribute to the emergence of new chemicals in agriculture. Antibacterial compounds obtained from medicinal and aromatic plants are considered as alternative to antibiotics and copper in the fight against bacterial diseases. 
Erwinia amylovora adlı bakteri, Rosaceae familyasına ait 39 farklı cinse dahil 128 türde ateş yanıklığı hastalığına neden olmaktadır (Beer ve Opgenorth, 1976). Yumuşak çekirdekli meyve türlerinin en tahripkar hastalığı olan ateş yanıklığı, bitkinin toprak altı ve toprak üstü aksamının tamamını enfekte edebilen ve sistemik hareket ettiğinden tüm bitkinin ölümüne sebep olabilen bir hastalıktır (Vanneste 2000; Gaaliche ve ark., 2017).

Yaklaşık 250 yıllık geçmişi olan hastalık, ülkemizde ilk kez 1985 yılında Afyon iline bağlı Sultandağı ilçesindeki armut bahçelerinde tespit edilmiştir (Öktem ve Benlioğlu, 1988). 1987 yılı itibariyle Türkiye'nin bütün armut yetiştirme alanlarında ateş yanıklığı belirtileri görülmüş ve çoğu bölgede ciddi zararlar oluşturarak pek çok bahçenin sökülmesine neden olmuştur (Momol ve Yeğen, 1993).

Hastalık etmeni, pek çok ülkede karantinaya tabi olmasına rağmen armut yetiştiriciliğinin yapıldığı yerlerde yaygın olarak görülmektedir (Kokoskova ve ark., 2011). Kimyasal mücadelenin kesin çözüm olmaması, insan ve çevre sağlığına olan olumsuz etkisi, kalıntı sorunlarına sebep olması ve organik yetiştiriciliğin her geçen gün tüketiciler arasında popülarite kazanması nedenleriyle; dayanıklı çeşit ile anaçların kullanımı, sanitasyon yöntemleri ve biyolojik mücadeleyi kapsayan entegre yöntemler hastalığın mücadelesinde öne çıkmaktadır (Mertoğlu ve Evrenosoğlu, 2017; Aktepe, 2018; Evrenosoğlu ve Mertoğlu, 2018).

Bakırlı preparat ve antibiyotik uygulamaları kısmen kontrol sağlamakta (Johnson ve Stockwell, 1998), ancak bu kimyasalların da pek çok dezavantajı bulunmaktadır. Patojen bakterinin antibiyotiklere direnç geliştirmesi, hedef dışı canlılara etkisi, doğal dengeyi bozması ve çevreyi kirletmesi gibi nedenlerle birçok ülkede kullanımı yasaktır (Iacobellis ve ark., 2005; Kokoskova ve ark., 2011). Bakırlı preparatlar ise vejetatif dönemde fitotoksik etkileri nedeniyle ancak dormant dönemde uygulanabilmektedir. Bu nedenle ateş yanıklığı hastalığının mücadelesinde alternatif yöntemlerin araştırılması zorunludur. Bu yöntemlerden birisi de doğal antimikrobiyal etkinliğe sahip olarak nitelendirilen, tıbbi ve aromatik bitki ekstraktları ve uçucu yağlarıdır.

Güçlü antibakteriyel aktiviteye sahip ve çevre dostu olan bitkisel uçucu yağlar, bitkisel ve gıda kökenli hastalık etmenlerin yanı sıra, bitki zararlıları ile mücadelede umut verici sonuçların alınmasını sağlamıştır (Soylu ve ark., 2009; Soylu ve ark., 2010; Sertkaya ve ark., 2010). Farklı uçucu yağların, Erwinia amylovora' ya karşı antibakteriyel etkilerinin araştırıldığı çalışmalarda, patojen gelişimini baskı altına aldığı bildirilmiştir (Scortichini ve Rossi, 1989; Scortichini ve Rossi, 1991; Basım ve ark., 2000; Basım ve Basım, 2004; Kokoskova ve Pavela, 2007; Karami-Osboo ve ark., 2010; Kokoskova ve ark., 2011; Salem ve ark., 2014). Ayrıca uçucu yağ uygulamalarının, bitkilerde sinyalizasyon ağı üzerine olumlu etkiler göstererek, dayanıklılık mekanizmasını etkilediği yapılan çalışmalarla ortaya konmuştur (Kokoskova ve ark., 2011; Umarusman, 2018). Bu amaçlar doğrultusunda, son yıllarda geliştirilerek piyasaya sürülen birçok biyopestisit bulunmaktadır. Etkilerinin hızlı ve net olmasına ilave olarak fiyatlarının uygun olması, rağbet görmelerini sağlamıştır (Isman, 2006). Etkilerinin, bakır veya diğer kimyasal bileşikler ile arttırılabileceği ve etken maddesinin sentetik olarak üretilerek, epideminin olduğu yer ve yıllarda güvenle kullanılabileceği belirtilmiştir (El-Astal, 2004; Kokoskova ve Pavela, 2007; Bajpai ve ark., 2011; Mengulluoglu ve Soylu, 2012).

Bu çalışmanın amacı, 16 farklı tıbbi ve aromatik bitkilerden elde edilen uçucu yağların in vitro koşullarda $E$. amylovora 'ya karşı antibakteriyel etkisini tespit etmektir.

\section{Materyal ve Yöntem}

Patojen Bakteri: Çukurova Üniversitesi Bitki Koruma bölümü bakteriyoloji laboratuvarı kültür koleksiyonunda bulunan tanısı yapılmış 69/1-1r kodlu Erwinia amylovora izolatı çalışmada kullanılmıştır. Bu izolat, İzmir'in Ödemiş ilçesinde 1993 yılında ayva ağacından izole edilmiştir (Aysan ve ark., 1994).

Uçucu Yağlar: Uçucu yağlardan zencefil ve ısırgan yağları Defne-Doğa (Antalya, Türkiye) firmasına ait ürünler olup, kullanılan tüm diğer yağlar Carl-Roth (Karlshure, Almanya) firmasının ürünleridir (Çizelge 1).

Çizelge 1. Uçucu yağların elde edildiği bitkiler

Table 1. Essential oils derived from plants

\begin{tabular}{ccc}
\hline Bitki Türü & Familyası & Yerel Adı \\
\hline Allium sativum & Amaryllidaceae & Sarımsak \\
\hline Artemisia absinthium & Asteraceae & Yavşan \\
\hline Cinnamomi ceylanici & Lauraceae & Tarçın \\
\hline Citrus limon & Rutaceae & Limon \\
\hline Cymbopogon citratus & Poaceae & Limon Otu \\
\hline
\end{tabular}




\begin{tabular}{ccc} 
(Çizelge 1 devami) & & \\
\hline Foeniculum vulgare & Apiaceae & Rezene \\
\hline Laurus nobilis & Lauraceae & Defne \\
\hline Lavandula officinalis & Lamiaceae & Lavanta \\
\hline Mentha arvensis & Lamiaceae & Nane \\
\hline Rosa sp. & Rosaceae & Gül \\
\hline Rosmarinus officinalis & Lamiaceae & Biberiye \\
\hline Salvia sclarea & Lamiaceae & Adaçayı \\
\hline Syzygium aromaticum & Myrtaceae & Baharat Karanfil \\
\hline Thymus vulgaris & Lamiaceae & Kekik \\
\hline Urtica sp. & Urticaceae & Isirgan \\
\hline Zingiber officinale & Zingiberaceae & Zencefil
\end{tabular}

Patojen İnokulumunun Hazırlanması: King B besi yerinde 48 saat geliştirilen Erwinia amylovora izolatından spektrofotometrede $600 \mathrm{~nm}$ dalga boyunda 0.2 ölçüm değerinde hazırlanan süspansiyondan seyreltme serisi hazırlanmıştır. Her bir seriden $100 \mu \mathrm{l}$ alınarak üç tekrarlı olarak King B besi yerine cam baget ile yayma işlemi yapılıp $25^{\circ} \mathrm{C}^{\prime}$ de 48 saat geliştirildikten sonra koloni sayımı yapılarak patojen popülasyonu $7 \times 10^{7}$ hücre $/ \mathrm{ml}$ 'ye ayarlanarak kullanılmıştır.

Antibakteriyel Etkinin Saptanması: Uçucu yağların Erwinia amylovora'ya antibakteriyel etkisi, in vitro petri denemeleriyle kağıt difüzyon disk yöntemine göre araştırılmıştır (Mangamma ve Sreeramulu, 1991; Mirik ve Aysan, 2005; Umarusman, 2018). King B besi yeri içeren $9.0 \mathrm{~cm}$ çaplı petrilere Erwinia amylovora'nın $7 \times 10^{7}$ hücre/ml popülasyonu içeren süspansiyondan $100 \mu$ leklenerek drigalski spatülüyle yayılmıştır. Petriler kuruduktan (yaklaşık 3 saat) sonra, $1 \mathrm{~cm}$ çapında yuvarlak steril kağıt disk birbirinden eşit uzaklıkta olacak şekilde petrilerin üç ayrı noktasına yerleştirilmiştir. Uçucu yağlardan $10 \mu \mathrm{l}$ alınıp kağıt disk üzerine damlatılmıştır. Negatif kontrol olarak steril su ve pozitif kontrol olarak streptomisin antibiyotiği (0.02gr/litre) kullanılmıştır. Deneme, her petride üç kağıt disk olmak üzere üç petri kullanılarak kurulmuştur. Petriler $25^{\circ} \mathrm{C}$ 'de 48 saat inkübe edildikten sonra kağıt disklerin çevresinde oluşan engelleme zonları (inhibisyon) mm olarak ölçülerek not edilmiştir.

Değerlendirme ve İstatistiksel Analiz: Uçucu yağların oluşturduğu engelleme zonları mm olarak ölçüldükten sonra antibakteriyel etki indeksi (AEI) pozitif kontrolle karşılaştırılarak aşağıdaki formüle göre hesaplanmıştır (Kokoskova ve Pavela, 2007; Kokoskova ve ark., 2011). AEI oranı uygulamaların streptomisine göre etkinin oranını ifade etmektedir. Bu oran grafik haline getirildiğinde grafiğin üzerinde yer alan uygulamalar streptomisinden daha etkili olan uygulamalarken, grafiğin altında kalanlar streptomisinden daha az etkiye sahip uygulamaları göstermektedir.1

AEI $(\%)=[-1 *(\mathrm{C}-\mathrm{T}) /(\mathrm{C}+\mathrm{T})]^{*} 100$

C: pozitif kontrolde (streptomisin) oluşan ortalama zon, T: uygulamada (uçucu yağ) oluşan ortalama zon

İnhibisyon zonu ölçümlerine göre elde edilen verilerle istatistiki analizler yapılmış ve uygulamalar arasındaki fark, ANOVA istatistik programında tek yönlü varyans analiziyle Duncan çoklu karşılaştırma testiyle \%5 önem düzeyinde değerlendirilmiştir. Aynı gruba giren uygulamalar aynı harfle işaretlenmiştir.

\section{Bulgular}

Çizelge 2'de ve Şekil 1'de görüldüğü gibi, denemeye alınan 16 adet uçucu yağın 11'i Erwinia amylovora'ya karş1 1.11 ile $16.44 \mathrm{~mm}$ arasında inhibisyon zonu oluşturarak antibakteriyel aktiviteye sahip olduğu saptanmıştır.

Artemisia absinthium, Citrus limon, Foeniculum vulgare, Urtica sp. ve Zingiber officinale türlerinden elde edilen uçucu yağlar, Erwinia amylovora'nın gelişimi üzerine herhangi bir engelleyici etkide bulunmamıştır. Rosa sp., Rosmarinus officinalis, Salvia sclarea ve Laurus nobilis uçucu yağlarında ise sırası ile 1.11, 1.78, 1.83 ve 2.39 mm'lik inhibisyon zonları ölçülmüş ve istatistiksel açıdan negatif kontrolle (steril su) aynı grupta yer alan etkisiz uygulamalar olduğu saptanmıştır (Çizelge 2).

Çalışma sonucunda, yedi uçucu yağın Erwinia amylovora'nın in vitro koşullarda gelişimini engellemede başarılı olduğu tespit edilmiştir. Pozitif kontrol olarak kullanılan streptomisin adlı antibiyotik, ortalama 5.11 mm'lik inhibisyon zonu oluşturmuştur. Cymbopogon citratus uçucu yağı ise 5.02 mm'lik engelleme zonuyla, istatistiksel olarak streptomisinle aynı grupta yer almış ve streptomisine eşdeğer etkiye sahip olduğu bulunmuştur. 
Diğer altı bitkinin (Allium sativum, Cinnamomi ceylanici, Lavandula officinalis, Mentha arvensis, Syzygium aromaticum ve Thymus vulgaris) uçucu yağı streptomisinden daha güçlü antibakteriyel aktiviteye sahip olmuştur. En kuvvetli antibakteriyel etkiye sahip uygulama ortalama 16.44 mm'lik inhibisyon zonuyla Allium sativum uçucu yağında kayıt edilmiştir. Bu uygulamayı $15.11 \mathrm{~mm}$ 'lik engelleme zonuyla Mentha arvensis ve $12.94 \mathrm{~mm}$ 'lik engelleme zonuyla Cinnamomi ceylanici uçucu yağları takip etmiştir. İstatistiksel olarak diğer bir grupta yer alan diğer başarılı uygulamalarda (Thymus vulgaris, Lavandula officinalis ve Syzygium aromaticum) ise sırasıly 9.83, 8.69 ve $7.55 \mathrm{~mm}$ engelleme zonu kaydedilmiştir. Erwinia amylovora' nın in vitro şartlarda gelişimini engellemede etkili bulunan bu uçucu yağlar, hastalığın mücadelesinde umut verici olarak değerlendirilmiştir.

Çizelge 2. Uçucu yağların Erwinia amylovora'ya antibakteriyel etkisi sonucu oluşan inhibisyon zonları (mm) ve antibakteriyel etki indeksi (AEI)

Table 2. Inhibitory zones (mm) and the antimicrobial efficacy index (IAE) resulting from the antibacterial effect of essential oils to Erwinia amylovora

\begin{tabular}{|c|c|c|}
\hline Uçucu Yăg & İnhibisyon zonu (mm) & AEI (\%) \\
\hline Allium sativum & $16.44 \mathrm{a}^{*}$ & 52,58 \\
\hline Artemisia absinthium & $0.00 \mathrm{e}$ & $-100,00$ \\
\hline Cinnamomi ceylanici & $12.94 \mathrm{~b}$ & 43,38 \\
\hline Citrus limon & $0.00 \mathrm{e}$ & $-100,00$ \\
\hline Cymbopogon citratus & $5.02 d$ & $-0,88$ \\
\hline Foeniculum vulgare & $0.00 \mathrm{e}$ & $-100,00$ \\
\hline Laurus nobilis & $2.39 \mathrm{e}$ & $-36,30$ \\
\hline Lavandula officinalis & $8.69 \mathrm{c}$ & 25,93 \\
\hline Mentha arvensis & $15.11 \mathrm{ab}$ & 49,45 \\
\hline Rosa sp. & $1.11 \mathrm{e}$ & $-73,47$ \\
\hline Rosmarinus officinalis & $1.78 \mathrm{e}$ & $-48,39$ \\
\hline Salvia sclarea & $1.83 \mathrm{e}$ & $-47,20$ \\
\hline Syzygium aromaticum & $7.55 \mathrm{c}$ & 19,30 \\
\hline Thymus vulgaris & $9.83 \mathrm{c}$ & 31,60 \\
\hline Urtica sp. & $0.00 \mathrm{e}$ & $-100,00$ \\
\hline Zingiber officinale & $0.00 \mathrm{e}$ & $-100,00$ \\
\hline Streptomisin (PK) & $5.11 \mathrm{~d}$ & \\
\hline Steril su (NK) & $0.00 \mathrm{e}$ & \\
\hline
\end{tabular}

AEI: antibakteriyel etki indeksi; mm: milimetre; PK: pozitif kontrol; NK: negatif kontrol

* Sütun içinde yer alan ortalama değerlerin $(n=3)$ yanındaki aynı harfler uygulamalar arasındaki farkın istatistiksel olarak önemli olmadığını gösterir (Duncan çoklu karşılaştırma Testi, $\mathrm{P} \leq 0.05$ )

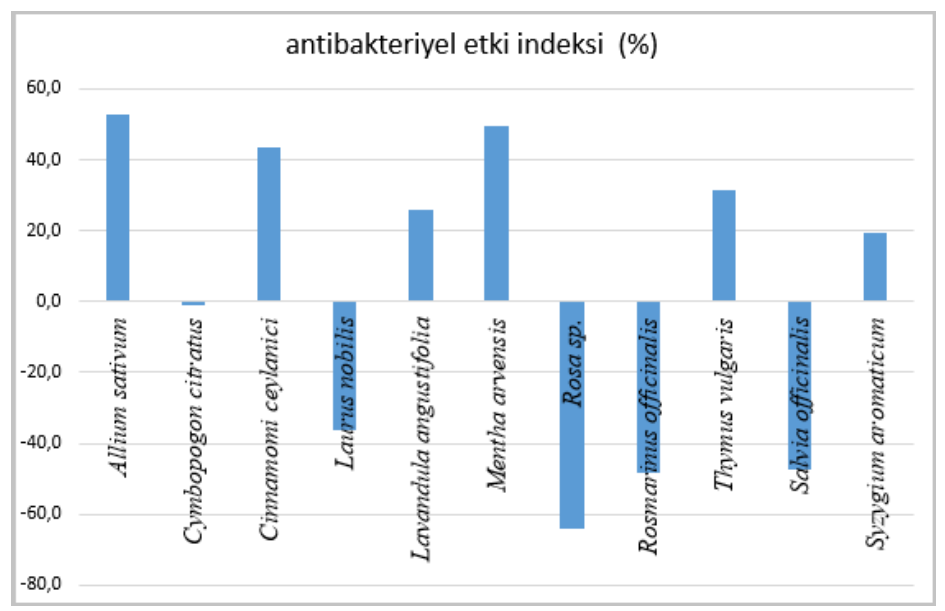

Şekil 1. Uçucu yağların Erwinia amylovora'ya karşı antibakteriyel etki indeksi

Figure 1. The antibacterial effect index of essential oils against Erwinia amylovora 


\section{Tartışma}

Tıbbi ve aromatik bitkilerin uçucu yağları güçlü antimikrobiyal etkileri ve çevre dostu olmalarından dolayı pek çok bitki koruma probleminin çözümünde alternatif olarak düşünülmektedir. Ateş yanıklığı hastalığının etmeni olan Erwinia amylovora'ya karşı in vitro koşullarda denenen, Mentha arvensis (Kokoskova ve Pavela, 2007; Kokoskova ve ark., 2011), Melissa officinalis (Kokoskova ve Pavela, 2007; Kokoskova ve ark., 2011), Nepeta cataria (Kokoskova ve ark., 2011), Origanum compacum (Kokoskova ve Pavela, 2007; Kokoskova ve ark., 2011), Origanum vulgare (Kokoskova ve Pavela, 2007; Kokoskova ve ark., 2011), Rosa damascena (Basım ve Basım, 2004), Thymbra spicata var spicata (Basım ve ark., 2000), Thymus vulgaris (Kokoskova ve Pavela, 2007; KaramiOsboo ve ark., 2010; Kokoskova ve ark., 2011), uçucu yağlarının patojeni baskılama üzerine olan olumlu etkileri daha önceki çalışmalarla ortaya konmuştur.

Bu çalışmada kullanılan uçucu yağlardan, Allium sativum, Mentha arvensis, Cinnamomi ceylanici, Thymus vulgaris, Lavandula officinalis, Syzygium aromaticum ve Cymbopogon citratus, patojen bakteri Erwinia amylovora'nın gelişimini in vitro koşullarda engellemiştir. Cymbopogon citratus hariç diğer etkili uçucu yağlar streptomisin antibiyotiğinden bile güçlü antibakteriyel aktivite göstermiştir.

Benzer sonuçlar, Mentha arvensis (Kokoskova ve Pavela, 2007; Kokoskova) ve Thymus vulgaris (Kokoskova ve Pavela, 2007; Karami-Osboo ve ark., 2010; Kokoskova ve ark., 2011) uçucu yağlarının kullanılarak elde edildiği bildirilmiştir. Erwinia amylovora'ya etkili bulunan diğer uçucu yağların antibakteriyel özellikleri ise ilk defa yapılan bu çalışmayla ortaya konmuştur. Mengulluoglu ve Soylu (2012) yapmış oldukları çalışmada Thymbra spicata L. subsp. spicata Thymus serpyllum L., Origanum majorana L., Mentha spicata L., Lavandula stoechas L. subsp. stoechas, Melissa officinalis L., Rosmarinus officinalis L. ve Ocimum basilicum L. uçucu yağlarının antibakteriyel etkinliklerini karpuz bakteriyel meyve leke hastalığ1 etmeni Acidovorax avenae subsp. citrulli’ye karşı araştırmış ve en etkili antibakteriyel etkinliğin $T$. spicata'dan elde edilen uçucu yağ tarafindan gösterildiğini belirlemiş olup, bu yağı sırasıyla T. serpyllum, O. majorana, M. spicata, M. officinalis, R. officinalis, L. stoechas ve $S$. officinalis uçucu yağlarının takip ettiğini bildirmiştir.

Rosa damascena'nın, Erwinia amylovora'ya antibakteriyel etkisi bilinmesine rağmen (Basım ve Basım, 2004), çalışmamızda kullanılan yağda (Rosa sp.) bu etki saptanamamıştır. Rosa damascena “Isparta Gülü” olarak adlandırılan, kendine özgü, zengin ve yoğun allelokimyasal içeren bir gül türüdür (Baydar ve Kazaz, 2013). Çalışmamızda kullandığımız gül yağının böylesine zengin bir kompozisyona sahip olmadığından aynı sonuca ulaşılamadığı düşünülmektedir. Ayrıca, tıbbı ve aromatik bitkilerin yetiştirildiği coğrafi alan, o yılki yetişme koşulları, bitkinin alt türlerinin varlığı, hasat zamanı, hasat şekli, depolama koşulları veya uçucu yağın elde edilmesinde kullanılan yöntemler uçucu yağ içeriği ve bileşenlerini etkileyebilir (Soylu ve ark., 2010; Kokoskova ve ark., 2011). Bu sayılan faktörlerden bir veya bir kaçının etkisiyle bizim çalışmamızda farklı sonuçlar elde edilmiş olabileceği düşünülmektedir.

Çalışmada Allium sativum, Cinnamomi ceylanici ve Mentha arvensis uçucu yağları Erwinia amylovora'ya karşı sergiledikleri güçlü antibakteriyel etkilerle dikkat çekici bulunmuştur. Allium sativum uçucu yağının ana bileşenlerinin diallyl trisulfide (\%33.57), diallyl sulfide (\%30.93) ve methyl allyl trisulfide (\%11.28)'den (Martinez-Velazuquez ve ark., 2011), Cinnamomi ceylanici uçucu yağının ana bileşenlerinin cinnammaldehyde (\%78.4) ve cinnamyl acetate (\%5.7)'dan (Park ve ark., 2005), Mentha arvensis uçucu yağının ana bileşenlerinin menthol (\%74.5), menthone (\%9.2) methyl acetate (\%3.1)'dan oluştuğu (Kokoskova ve ark., 2011) bilinmektedir. Uçucu yağların bileşenlerini oluşturan bu kimyasalların Erwinia amylovora'ya karşı antibakteriyel etkiye sahip olduğu düşünülmektedir.

Tıbbi ve aromatik bitkilerden elde edilen çeşitli ekstraktlar ve/veya onların uçucu yağları, doğal bakterisitler olarak görev yapmakta olup, bitki bakteriyel hastalıklarının mücadelesinde entegre mücadelenin bir parçası olarak kullanılması umut verici bir alternatif olarak görülmektedir. Bu uçucu yağlarının etken maddeleri tarımda yeni kimyasalların ortaya çıkışına katkı sağlamaktadır. Tıbbi ve aromatik bitkilerden elde edilen antibakteriyel bileşikler, bakteriyel hastalıkların mücadelesinde antibiyotiklerin ve bakırın alternatifi olarak değerlendirilmiştir (Soylu ve ark., 2009; Mengulluoglu ve Soylu, 2012; Savoia, 2012; Umarusman, 2018). Antibiyotik kullanımına bağlı olarak, bakteri kökenli hastalık etmenlerinin dayanıklı formlar geliştirmesinin (Förster ve ark., 2015) engellenmesi bakımından, uçucu yağların entegre mücadele kapsamında kullanımı son derece önemlidir (Gwinn, 2018). Ayrıca başta ıslah çalışmaları olmak üzere, melezlemeler sonucu elde edilen tohumlar, toprak kökenli çürükçül patojenlere karşı oldukça hassastırlar (Evrenosoğlu ve ark., 2011). Melezleme ıslahı ile yeni çeşitlerin geliştirilmesi sürecinde, melez bitkilerin elde edileceği tohumlar, Erwinia amylovora gibi sistemik yayılan hastalıklara karşı infeksiyon tehdidi altındadır (Thomson, 1986; Vanneste, 2000, Farkas ve ark.,2012). Umut verici bulunan; Allium sativum, Cinnamomi ceylanici ve Mentha arvensis uçucu yağları, ekim öncesi tohum uygulamaları ve tarım aletlerinin temizliği noktasında kullanımı önerilmektedir. Direk bitki uygulamaları ise yapılacak olan in vivo denemeler sonrası mümkün olacaktır. 


\section{Kaynakça/References}

Aktepe, B.P. 2018. Erwinia amylovora'nın Biyolojik Mücadelesinde Epifitik Bakteri ve Mayaların Etkilerinin Araştırılması. Çukurova Universitesi Fen Bilimleri Enstitüsü, Bitki Koruma Anabilim Dalı, Doktora Tezi, Adana, 109s.

Aysan, Y., Tokgonul, S., Çınar, Ö. and Kuden, A. 1994. Reaserchers on resistant reactions of pears against Erwinia amylovora (Burr.) Winslow et al. In: Proceedings of $9^{\text {th }}$ Congress of the Mediterranean Phytopathological Union, 18-24 September, Kuşadas1-Turkey: $311-313$.

Bajpai, V. K., Kang, S. R., Xu, H., Lee, S. G., Baek, K. H. and Kang, S. C. 2011. Potential roles of essential oils on controlling plant pathogenic bacteria Xanthomonas species: a review. The Plant Pathology Journal, 27 (3): 207-224.

Basim, H., Yegen, O. and Zeller, W. 2000. Antibacterial effect of essential oil of Thymbra spicata L. var. spicata on some plant pathogenic bacteria. Journal of Plant Disease and Protection, 279 (3): 279-284.

Basım, E. and Basım, H. 2004. Note: evaluation of antibacterial activity of essential oil of Rosa damascena on Erwinia amylovora. Phytoparasitica 32:409-12.

Baydar, H., and Kazaz, S. 2013. Yağ Gülü \& Isparta Gülcülüğü. Gülbirlik Yayınları, (1).

Beer, S. V. and Opgenorth, D.C. 1976. Erwinia amylovora on fire blight canker surfaces and blossoms in relation to disease occurrence. Phytopathology, 66: 317-322.

El-Astal Z. 2004. Bacterial pathogens and their antimicrobial susceptibility in Gaza Strip, Palestine. Pakistan Journal of Medical Sciences, 20 (4): $365-370$

Evrenosoğlu, Y., and Mertoğlu, K. 2018. Evaluation of pear (Pyrus communis L.) hybrid combinations for the transmission of fire blight resistance and fruit characteristics. Czech Journal of Genetics and Plant Breeding, 54 (2):78-85

Evrenosoğlu, Y., Misirli, A., Saygili, H., Bilen, E., Boztepe, Ö., and Acarsoy, N. 2011. Evaluation of susceptibility of different pear hybrid populations to fire blight (Erwinia amylovora). Notulae Botanicae Horti Agrobotanici Cluj-Napoca, 39 (1): $226-236$.

Farkas, A., Mihalik, E., Dorgai L. and Buban, T. 2012. Floral traits affecting fire blight infection and management. Trees, 26:47-66.

Förster, H., McGhee, G. C., Sundin, G. W. and Adaskaveg, J. E. 2015. Characterization of streptomycin resistance in isolates of Erwinia amylovora in California. Phytopathology, 105 (10):1302-1310.

Gaaliche, B., Chehimi, S., Dardouri, S. and Hajlaoui, M. R. 2017. Health status of the pear tree following the establishment of fire blight in Northern Tunisia. International Journal of Fruit Science, 1-14.

Gwinn, K. D. 2018. Bioactive natural products in plant disease control. Studies in Natural Products Chemistry, 56: 229-246.

Iacobellis, N., Lo Cantore, P., Capasso, F. and Senatore, F. 2005. Antibacterial activity of Cuminum cyminum L. and Carum carvi L. essential oils. Journal of Agricultural and Food Chemistry 53 (1): 57-61.

Isman, B.M. 2006. Botanical insecticides, deterrents, and repellents in modern agriculture and an increasingly regulated World. Annual Review of Entomology, 51 (1):45-66.

Johnson, K.B. and Stockwell, V.O. 1998. Management of fire blight: a case study in microbial ecology. Annual Review of Phytopathology, 36: $227-48$.

Karami-Osboo, R., Khodaverdi, M. and Ali-Akbari, F. 2010. Antibacterial effect of effective compounds of Satureja hortensis and Thymus vulgaris essential oils against Erwinia amylovora. Journal of Agricultural Science and Technology, 12 (1): 35-45.

Kokoskova, B. and Pavela, R. 2007. Effectiveness of plant essential oils on the growth of Erwinia amylovora, the causal agent of fire blight disease. Pest Technology, 1 (1): 76-80.

Kokoskova, B. Pavela, R. and Pouvova, D. 2011. Effectiveness of plant essential oils against Erwinia amylovora, Pseudomonas syringae pv. syringae and associated saprophytic bacteria on/in host plants. Journal of Plant Pathology, 93 (1): 133-139.

Mangamma, P., and Sreeramulu, A. 1991. Garlic extract inhibitory to growth of Xanthomonas campestris pv. vesicatoria. Indian Phytopathology, $44(3): 372-374$.

Martinez-Velazquez, M., Rosario-Cruz, R., Castillo-Herrera, G., Flores-Fernandez, J. M., Alvarez, A. H. and Lugo-Cervantes, E. 2011. Acaricidal effect of essential oils from Lippia graveolens (Lamiales: Verbenaceae), Rosmarinus officinalis (Lamiales: Lamiaceae), and Allium sativum (Liliales: Liliaceae) Against Rhipicephalus (Boophilus) microplus (Acari: Ixodidae). Journal of Medical Entomology, 48 (4): $822-827$.

Mengulluoglu, M., Soylu, S. 2012. Antibacterial activities of essential oils extracted from medicinal plants against seed-borne bacterial disease agent, Acidovorax avenae subsp citrulli. Research on Crops, 13: 641-646.

Mertoğlu, K. and Evrenosoglu, Y. 2017. Phenological and fruit characteristics of the F1 hybrid pear population tested against the disease in breeding for fire blight resistance. Journal of Tekirdag Agricultural Faculty 14 (3): 104-115.

Mirik, M. and Aysan, Y. 2005. Effect of some plant extracts as seed treatments on bacterial spot disease of tomato and pepper. The Journal of Turkish Phytopathology, 34 (1-2-3).

Momol, T. and Yegen, O., 1993. Fire blight in Turkey. Acta Horticulturae, 338: 37-40.

Öktem, Y. E. ve Benlioğlu, K. 1988. Yumuşak çekirdekli meyve ağaçlarında görülen ateş yanıklığı hastalığ 1 (Erwinia amylovora (Burr.) Winslow et.al.) üzerine çalışmalar. V. Türkiye Fitopatoloji Kongresi (18-21 Ekim 1988) Bildiri Özetleri, TÜBİTAK Yayınları No: 643, TOAG Seri No: 128:71.

Park, I., Park, J., Kim, K., Choi, K., Choi, I., Kim, C. and Shin, S. 2005. Nematicidal activity of plant essential oils and components from garlic (Allium sativum) and cinnamon (Cinnamomum verum) oils against the pine wood nematode (Bursaphelenchus xylophilus). Nematology, 7 (5): 767-774. 
Salem, M. Z. M., Ali, H. M. and Basalah, M. O. 2014. Essential oils from wood, bark, and needles of Pinus roxburghii Sarg. from Alexandria, Egypt: Antibacterial and antioxidant activities. BioResources, 9 (4): 7454-7466.

Savoia, D. 2012. Plant-derived antimicrobial compounds: alternatives to antibiotics. Future microbiology, 7 (8): 979-990.

Scortichini, M., and Rossi, M. P. 1989. In vitro activity of some essential oils toward Erwinia amylovora (Burr.) Winslow et-al. Acta Phytopathologica et Entomologica Hungarica, 24 (3-4): 423-431.

Scortichini, M and Rossi, M.P. 1991. In vitro susceptibility of Erwinia amylovora (Burrill) Winslow et al. to geraniol and citronelloli. Journal of Applied Microbiology, 71 (2): 113-118.

Sertkaya, E., Kaya, K., Soylu, S. 2010. Acaricidal activities of the essential oils from several medicinal plants against the carmine spider mite (Tetranychus cinnabarinus Boisd.) (Acarina: Tetranychidae). Industrial Crops and Products, 31: 107-112

Soylu, S., Soylu, E.M., Evrendilek, G.A. 2009. Chemical composition and antibacterial activity of essential oils of bitter fennel (Foeniculum yulgare Mill. var. vulgare) and dill (Anethum graveolens L.) against the growth of food-borne and seed-borne pathogenic bacteria. Italian Journal of Food Science, 21: 347-355

Soylu, E.M., Kurt, S., Soylu, S. 2010. In vitro and in vivo antifungal activities of the essential oils of various plants against tomato grey mould disease agent Botrytis cinerea. International Journal of Food Microbiology, 143: 183-189

Thomson, S. V. 1986. The role of the stigma in fire blight infections. Phytopathology 76:476-482.

Umarusman, M.A. 2018. Farklı Bitki Ekstraktlarının Bezelye Bakteriyel Yaprak Yanıklı̆ına (Pseudomonas syringae pv. pisi) Antibakteriyel Etkilerinin Araştırılması. Çukurova Üniversitesi Fen Bilimleri Enstitüsü, Bitki Koruma Anabilim Dalı, Yüksek Lisans Tezi, Adana, 64s.

Vanneste, J.L. 2000. Fire Blight The Disease and Its Causative Agent, Erwinia amylovora. CABI Publishing, 370p. 